\title{
Docência Crítica, Reflexos de Autonomia
}

\author{
Ariel Erick Paulo de Souza1 \\ Universidade Severino Sombra (USS), CELCSAH, Curso de Letras, \\ arielturunemehotmail.com \\ Cláudio Rodrigo Gomes da Silva \\ Universidade Severino Sombra (USS), CELCSAH, Curso de Letras, \\ rodrigo_azurro@hotmail.com \\ Lucas Ferreira Rodrigues da Silva \\ Universidade Severino Sombra (USS), CELCSAH, Curso de Letras, \\ lucas_usseyahoo.com.br \\ Rafael Italo Fernandes da Fonseca \\ Universidade Severino Sombra (USS), CELCSAH, Curso de Letras, \\ rafael.iff@globo.com \\ William Teixeira Alves \\ Universidade Severino Sombra (USS), CELCSAH, professor \\ orientador, wyl.alvesabol.com.br
}

\begin{abstract}
Resumo: Este ensaio objetiva considerar a prática educativa, de modo a contemplar uma postura crítico-reflexiva do docente, conforme o ideário de António Nóvoa (2007), nas construções da própria identidade e da busca por gerar caráter autônomo na edificação discente dos saberes. Ademais, visa a suscitar - ao corpo docente interessado e aos que se graduam em proximidade a temas educacionais - o desejo de querer trabalhar práticas que possibilitem universos de liberdade e reflexão na sala de aula proposta por Paulo Freire (2010). Outro ponto que será considerado é a proposta em tríade de Schön: reflexão na ação, reflexão sobre a ação e reflexão sobre a reflexão na ação. Além dos autores citados, estabeleceremos base também em Alarcão (1996), Azzi (2009) e Garrido Pimenta (2009).
\end{abstract}

Palavras-chave: Educação. Reflexão. Identidade docente. Autonomia

\section{Enseñanza Crítica, Reflejos de Autonomía}

Resumen: Este artículo tiene como objetivo considerar la práctica educativa, así contemplando una posición crítica y reflexiva del profesor, de acuerdo con las ideas de António Nóvoa (2007), en la construcción de su propria identidady de la búsqueda de la generación de carácter autónomo en la edificación de los conocimientos por el alumno. Más allá de eso, el trabajo tratará de estimular - a los profesores y a los que hacen profesorado o algo similar - el deseo de utilizar prácticas que permiten la libertad y reflexión en el aula de clase 
indicada por Paulo Freire (2010). Otro aspecto es la propuesta en la tríada de Schön: reflexión en la acción, sobre la acción y sobre la reflexión en la acción. Además de los autores acima, también encontraremos base en Alarcão (1996), Azzi (2009) y Garrido Pimenta (2009).

Palabras clave: Educación. Reflexión. Indentidad del profesor. Autonomía.

\section{Dodiscência Crítico-Reflexiva}

Ao longo dos últimos anos, o tema "ensino crítico-reflexivo" tem estado muito em vista, a tem ganhado ênfase em muitos países do mundo. Mesmo os que não o têm como diretriz básica de ensino têm feito muitas pesquisas de aplicabilidade. Em sua pesquisa, Alarcão (1996) levanta uma série de questões que podem ajudar a refinar os conceitos em relação à prática crítico-reflexiva, e também responder a muitas das questões que ainda pairam na mente de muitas pessoas, inclusive estudiosos do tema. São elas:

. Por que perguntar-se se é tempo de ser reflexivo?

- O que é ser reflexivo?

. Quem deverá ser reflexivo?

- Para que ser-se reflexivo?

. Sobre o que ser-se reflexivo?

. Como ser-se reflexivo?

. É possível ser-se reflexivo?

- É desejável ser-se reflexivo?

. Para onde vamos com a nossa reflexão?

É fato que, como citamos antes, com todo o movimento em torno do pensamento críticoreflexivo e com o espaço que ele tem ganhado, é imprescindível que não fiquemos indiferentes ou nos limitemos à posição de expectadores. Devemos ao contrário, tomar parte dessa tendência e fazer o máximo para torná-la, cada vez mais, influente em nossa realidade. Principalmente, por fazermos parte do grupo de países que ainda não tem essa prática estabelecida em nosso sistema de ensino.

Mas, obviamente, não devemos simplesmente aderir ao que está sendo feito por aí, simplesmente por ser uma tendência emergente e concordarmos com a ideia. O próprio nome já diz: "prática crítico-reflexiva". Para adentrarmos a esse círculo, com contribuições válidas e relevantes, é crucial que haja uma forte reflexão sobre o que fazer, por que fazer e como fazer, pois do contrário, estaríamos mecanizando a reflexão e nos tornando aquilo que pregamos ser contra e ainda submissos a um sistema, e sob esse ideário a autonomia seria falsa ou inexistente. 
A humanidade contemporânea mostra-se necessitada de uma libertação intelectual, em que possa traçar seu próprio futuro e escolher o seu destino e o de sua raça. É notada uma atitude inquieta e questionadora, em busca da aquisição de uma identidade que satisfaça o ego e a moral das pessoas. E é por meio da prática crítico-reflexiva que o homem tem sido capaz de reorganizar seus conceitos e elaborar novas diretrizes para a conquista de uma postura satisfatória. Por meio da autonomização o homem tem conseguido se libertar de regras e processos de mecanização aos quais se via preso ao longo de muitas décadas. A autonomia intelectual gera pessoas mais dispostas a buscar os porquês por trás dos porquês e se questionarem o porquê de não se ter questionado antes e se devem ou não manter ou reformular seus fundamentos ideológicos. Isso os torna capazes de reaprender a pensar, fugindo dos grilhões criados pelos pensadores passados que não lhe servem mais aos pulsos, e passam a refletir para agir sob novos conceitos, adequados ao século XXI.

Como abordamos anteriormente, é necessário, mesmo que sendo uma tarefa difícil, determinar os conceitos do que é ser reflexivo ou não. Apesar de ser impossível criar uma lista de regras básicas e fixas, com procedimentos e pensamentos imutáveis, podemos arquitetar uma série de fundamentos que propiciam uma abordagem crítico-reflexiva. Um desses fundamentos está relacionado à submissão e mecanização a que tendemos a nos deixar levar. O agir sem refletir, sem questionar, a ausência de curiosidade sobre nossos próprios afazeres está totalmente contra o conceito de autonomia. É necessário dedicação especial, simultaneamente, ao lógico e ao psicológico, à racionalidade e ao afeto, à intuição e à paixão, para alcançar tal objetivo. Ação e reflexões ativas e voluntárias são essenciais na busca pela verdade e luta pela justiça que se acredita, em atitude persistente e rigorosa. Mais difícil que atingir uma postura crítico-reflexiva é mantê-la. Não foram poucos os pensadores reflexivos que se deixaram mecanizar e perderam sua iniciativa e determinação autônoma sem nem mesmo perceber. Ou então que se mantiveram presos a uma autonomia estática por anos a fio, tornando-se mecanizados e perdendo os objetivos reflexivos. A postura crítica tem que sempre ser renovada, ela não é ela está. É imprescindível que ela seja, sempre, remodelada de acordo com os conceitos temporal e espacial no qual será aplicada. Todas as ações reflexivas devem ser justificadas por uma convicção real ou conceito na qual foi aplicada. Uma abordagem no local X deverá ser diferente do que teria sido dez anos antes, da mesma forma que a reflexão sobre fatos semelhantes, acontecendo ao mesmo tempo em locais $\mathrm{X}$ e $\mathrm{Y}$ deverão ser analisados como fatos únicos e com pouquíssimas ou, talvez, nenhuma relação.

Outro ponto chave para uma perspectiva docente crítico-reflexiva é a consciência de que seus deveres não se limitam aos muros da escola ou às paredes das salas de aula. Ser educador é pensar e agir como tal também fora do ambiente de trabalho, em seu dia a dia. É estar presente e ativo nos planejamentos e projetos das escolas e comunidades da qual faz parte. Sendo possível assim conhecer e agir em totalidade para o avança e desenvolvimento de ambos. Agindo sob uma perspectiva crítica completa, o educador ampliará a eficiência de sua reflexão e proverá uma contribuição autônoma verdadeira às suas sociedades. 
Schön definiu três requisitos essenciais para um professor crítico reflexivo desenvolver seus atributos e aplicar com sucesso a autonomização: a reflexão na ação, que seria uma reflexão feita sobre uma atividade no momento da prática em pequenos instantes de distanciamento, avaliando a sucesso alcançado até ali e o caminho ideal a se tomar; a reflexão sobre a ação, uma reflexão sobre a ação como um todo, observando erros e acertos, definindo possíveis novas abordagens e analisando as consideradas adequadas; e, a reflexão sobre a reflexão na ação, um balanço tanto sobre as práticas consideradas apropriadas como os métodos de reflexão utilizados para se chegar à conclusão de que essas práticas de fato são ideais a seus fins.

Segundo os estudos de Alarcão (1996), podemos afirmar que "[...] a dimensão de promoção da autonomia pela reflexão parece mais nítida no caso dos alunos, enquanto que a dimensão de reflexão autônoma é destacada no caso dos professores [...]”. Pela perspectiva do aluno, poderíamos afirmar que seu papel é refletir sobre si quanto ao que faz e ao que é ser aluno; ser instruído por outra pessoa a construir seus conhecimentos. Quanto a seu objeto de estudo ele refletir sobre seu objeto de estudo e os métodos que poderá utilizar para construir esse aprendizado com maior eficiência.

Outra prática de extrema importância ao educador reflexivo é a de não somente recordar os conceitos aprendidos e desenvolvidos ao longo de sua experiência, mas principalmente compreender sua função, não se limitando a somente armazenar sua ideia. Na tentativa de compreensão de uma ideia ou um acontecimento há de ser feita uma análise completa da ação, da atitude, do fenômeno e todas as coisas que geraram e foram gerados pelo objeto de estudo, para que esse faça sentido e o sentido observado possa ser o mais fiel à realidade possível.

É nesse ponto que consideramos, então, todos os aspectos passíveis de reflexão. Desde caracteres sociolinguísticos até considerações metacognitivas e de auto-observação. Nenhum deles pode ser alheio à crítica do ensino.

Alarcão (1996), quanto a isso, recomenda ao professor: "conhece a tua profissão e conhece-te a ti mesmo como professor para te assumires como profissional de ensino. [...] Descobre o sentido da tua profissão". Esse fundamento é, de fato, essencial na compreensão de uma prática educativa consciente, na qual se estabelecem relações fortes entre uma docência refletida e uma aprendizagem eficaz alcançada pela autonomia do discente. Se esse processo é dialético, temos que também o fato de que "a razão de ser dos professores é a existência do aluno e este, na sua qualidade de aluno [...] não existe sem aquele" (ALARCÃO 1996:181).

É na reflexão da prática educativa que novos conceitos se constroem. Se isso por acaso, não ocorrer, certamente haverá, por outro lado, substituição de pensamentos, remodelações de métodos ou exclusão de atitudes anteriores agora tidas por inválidas. Todo esse processo corrobora com o fato de que o pensamento reflexivo é, sim, um potencial, uma capacidade que, como as outras, não surge, mas se desenvolve. Mas de que maneira ser reflexivo?

Destaca-se que um ponto de grande importância é o questionamento. Ele define o caráter autorreflexivo do professor e afirma a compreensão de si e do que à volta se encontra. $\mathrm{O}$ cerne investigativo do processo crítico tende a emergir à tona para o docente questionador e 
a provocar conclusões. A busca introspectiva por resoluções é capaz de suscitar mudanças através da constante "visita" ao histórico de experiências daquele que ministra as aulas e, conseguintemente, acumula vivência profissional. Para ter sucesso em seu projeto de mudança através dos próprios conceitos, é necessário que esse caráter seja revestido de envolvimento tanto na investigação quanto na descoberta.

São as perguntas e suas respostas que potencializam o professor à reconstrução. Alarcão, em sua obra, cita as tarefas formativas estabelecidas por John Smyth (1989): "descrição, interpretação, confronto e reconstrução" (ALARCÃO 1996:182).

Essa estratégia é, à luz da perspectiva crítico-reflexiva, o processo mais aprimorado pelo qual o professor passa a fim de juntar-se firme à vontade de mudança e, de fato, à própria transformação. Um profissional insatisfeito, que não se imagina em contextos de ensino ideais e que não estabelece um paralelo entre esses e a prática que tem, tende a cair na própria armadilha do apego à docência desestimulante coberta pelo medo de mudar e pela mentira da aceitação passiva dos entraves educacionais que enfrenta.

E é na busca e no zelo por não se ver nessa situação que o docente tem de investigar agindo. Mais importante que a análise autobiográfica dos métodos de classe é a "investigaçãoação" (ALARCÃO 1996:182).

Deve-se viabilizar uma comparação consciente entre os projetos reflexivos de trabalho e aqueles que se quer aplicar em sala de aula ao discente. Esse paralelo entra em um universo, de impossível recorte, que também abarca a transformação. A essa prática só é atribuído sucesso, no entanto, quando não há inequívocas adequações entre finalidades, conteúdo e estratégias.

É de modo essencial que se deve assimilar o fato de que o retrospecto da prática deve ser associado com o prospecto adequado e devidamente pensado para projeções eficazes na prática vindoura. Os futuros planejamentos devem condizer com o rumo da ação, que, por sua vez, devem condizer com o estado atual da docência.

Paulo Freire (2010) chama a atenção para uma consideração escolar dos conhecimentos empíricos, de base gnosiológica, do discente no processo de ensino-aprendizagem. $\mathrm{O}$ encaixe entre a informação científica e a carga que o aluno tem de vivência cognitiva e afetiva leva a um aprimoramento vantajoso da formulação mediada de saberes. O conhecimento que está para além das anotações pessoais deve ser entendido como ferramenta de busca por adequação entre a praxis das lições a nível intelectual e a vivência de quem as faz em nível de experiência vivida. Eis dois aspectos inseparáveis.

Não só, contudo, de reflexões por parte do docente deve viver o cenário educacional. É crucial que ao aluno também pertença o caráter crítico de seu aprendizado enquanto ente social em constante (re)construção empírica e epistemológica.

"Os alunos podem, e devem, refletir sobre [...] o que aprendem numa perspectiva formal e funcional, sobre a relevância individual e social da sua aprendizagem [...], sobre as capacidades que desenvolvem, sobre o papel que, como alunos, desempenham" (ALARCÃO 1996:180). 
Dessa forma, faz-se necessário que o professor desempenhe papel estimulante na reflexão de seu alunado tanto no que diz respeito à ciência estudada quanto no que tange o universo da compreensão de integração no mundo social. É o que postula Celso Antunes (2007): “[...] propor novas situações de aprendizagens pesquisadas e através das mesmas provocar reflexões, despertar argumentações, estimular competências e habilidades" (ANTUNES 2007:14).

Voltando ao caso do docente, tem-se como certo o fato de que a exigência do processo de reflexão torna a construção do caráter crítico algo de difícil alcance. É um obstáculo que exige vontade e paciência para ser superado. O que caracteriza uma modalidade fechada e tradicional de ensino também figura como ponto negativo provindo de algumas instituições para o processo autorreflexivo. É o que o excerto de Douglas Altamiro Consolo (2003) referencia:

\footnotetext{
"Em vez de promover a reflexão, prepara-se o professor para recorrer a 'peças que se encontram ao lado do 'quebra-cabeças', como no caso de planos de aulas 'que sempre 'dão certo', e de acervos de materiais didáticos especialmente reunidos e direcionados para cada aula dos cursos planejados" (CONSOLO 2003:58).
}

Nota-se que o caso da postura crítica envolve uma série de benefícios, mas que se encontram sobre um solo desconfortável de exigências e descaso para com a mudança que pode transformar o modo de ensinar ciência. É certo, porém, que "ninguém deve ser obrigado a ser reflexivo, embora todos devam ser estimulados a sê-lo. E o todo começa em cada um de nós" (ALARCÃO 1996:186).

A disposição para a mudança também é marcador de desejo profissional, porquanto aquele que ensina com prazer tem em mente que retrospectos e projeções são constantemente necessários para a docência. $O$ professor deve apreender que sua postura crítica mediante seus próprios métodos constitui acréscimos em sua formação, que deve ser perpetuamente construída e reconstruída e refletir no cerne de sua identidade. Sendo assim, todos os processos de mediação servirão para gerar o caráter discente autônomo, absolutamente adequado na visão de prática educativa libertadora (FREIRE 2010). Serão esses temas abordados a seguir.

\section{Identidade Social}

Busca-se estudar a construção da identidade como um elemento em constante transformação, que ocorre a partir de práticas sociais que advogam a criação de discursos conforme cada ser social faz. Santos (1990) destaca, como aspecto principal do conceito de identidade, o reconhecimento que emana das relações sociais. Santos ainda releva que, o indivíduo define-se a partir de como se reconhece no desempenho de papéis sociais e de como é reconhecido pelos outros no meio social.

Enfim, considerar a identidade inserida neste contexto sociocultural implica na concepção 
do sujeito humano como portador da capacidade de representar, de criar e compartilhar significados em relação a tudo com o que convive.

\section{Identidade Discente}

Para melhor interpretar o conceito de identidade docente, o que será explanado a seguir, é igualmente necessário conhecer uma das mais importantes identidades, para a qual o professor auxilia o processo de estruturação e modelagem: a identidade discente.

Primeiramente, o profissional da educação deve estar ciente de que possui papel de mediador e estruturador parcial, de importância mais que relevante, de conhecimentos e opiniões. Sua prática pode influenciar a conduta de um aluno perpetuamente, posto que em sala de aula, o professor possui uma imagem de imponência perante seus alunos, que é exatamente o que Freire (2010) contraria. Ele o faz ao dizer que apesar de ser necessária uma rigorosidade metódica docente, não é preciso que se demonstre uma figura impositiva, tirana, para os educandos, porque isso pode levar a uma recusa para com o próprio tutor e, consequentemente, para com sua disciplina.

Em meio ao ambiente escolar há um encontro considerável de culturas e ideologias políticas. Depende, claro, da área em que atua o professor: neste caso, o ensino médio. A partir desse conflito cultural é que o educador, por sua vez, cria interação com seus alunos a fim de estimular-lhes a produção de conhecimentos, perspectivas e intenções profissionais.

No entanto, estes estímulos são especialmente direcionados para o aparecimento do pensamento autônomo, enunciado por Freire (2010). Uma vez produzido tal feito, esse aluno, futuro profissional - seja da educação, saúde, política, entre outras áreas -, certamente possuirá visões de mundo divergentes das dos demais.

\section{Identidade Docente}

A identidade docente é construída a partir das crenças que o profissional da educação possui, de sua experiência de vida, estrutura familiar e, principalmente, a partir da reflexão de sua prática docente. Sendo ele um ente histórico, tudo, inclusive sua produção, também o será. (PAULINO 1989)

Assim, a identidade é formada a partir do ente social "professor", uma vez que suas vivências são fundamentais para a estruturação do seu caráter, sua postura e, consequentemente, de sua atuação durante o exercício da função docente.

Além disso, a construção da identidade não pode ser concebida como um processo isolado. Existe sempre uma relação com outro - real ou imaginário específico ou genérico - para quem se apresenta e, por isso mesmo, é, mais que tudo, um acontecimento social e coletivo.

Ao analisar a formação docente na contemporaneidade, fica clara a falta de preparo de alguns profissionais para com a área da educação. Devido a alguns problemas como: a) compreensão inadequada do conteúdo abordado; b) professores mal instruídos 
pedagogicamente, e, principalmente, c) falta de criatividade para inovar e reorganizar suas práticas docentes.

A questão primordial para o docente é assumir postura de mediador de saberes, e tomar consciência de que seu papel em meio à sociedade possui influência direta na opinião não só discente, como na da sociedade em um todo.

No universo da prática educativa, o professor necessita buscar a reflexão de sua identidade, bem como de sua ação, para estar cada vez mais preparado e passível à aquisição de conhecimentos empíricos e gnosiológicos para desenvolver-se como demanda o mercado de trabalho fixo em ideias liberais (FREIRE 2010).

Sendo assim, a identidade do professor deve ser permeada sempre pela reflexão, pois é através dela que o docente é capaz de alcançar (re)aprimoramento como profissional e cidadão.

\section{Autonomia}

Quando o educador reflete nas/sobre suas práticas, ele constrói seus saberes pedagógicos e didáticos articulando seus conhecimentos específicos com sua experiência. Isso possibilita que o educador obtenha um conhecimento sobre quais de suas práticas devem permanecer e quais devem sofrer alterações para melhor se adaptarem ao contexto em que se encontram.

Durante algum tempo, a educação técnica e arbitrária foi suficiente e não apresentou problemas, contudo, as propostas de reforma na educação e a tendência da reflexão, típicas do final do século XX, possibilitaram uma forma diferente de se enxergar as práticas pedagógicas.

\section{O Professor do "Ensino Bancário"}

A racionalidade técnica, que transformou os professores em meros reprodutores de conhecimento é um dos principais problemas que atrapalham o bom desempenho da atividade docente. Segundo Freire, essa educação bancária desestimula a criatividade do educando e do educador e caracteriza professores sem a autonomia necessária para que a dinâmica na sala de aula ofereça com êxito a possibilidade de formar alunos críticos.

É-se necessário apreender que "ensinar não é transferir conhecimento, mas criar as possibilidades para a sua produção ou a sua construção" (FREIRE 2010:22).

\section{O Câmbio de Conhecimentos entre Professor e Aluno}

Os professores não devem se aceitar como formadores ou considerar os alunos como objetos a serem formados. É preciso que se tenha o conhecimento da troca de informações, a qual, aluno e professor se formam igualmente. "Quem ensina aprende ao ensinar e quem aprende ensina ao aprender” (FREIRE 2010:23). 
Essa troca de conhecimentos permite melhores condições de interação entre professor e aluno. Tal teoria, de caráter vigotskyano, afirma que o conhecimento se dá a partir da interação entre indivíduos. A criança não apenas sofre influência, mas também exerce influência no meio em que se encontra. Nesse caso, a interação entre professor e aluno é o que possibilita a construção do conhecimento.

\section{A Importância dos Saberes do Educando para a Autonomia}

Para que o educador baseie sua autonomia na troca de informações entre ele e o aluno, é necessário também que ele respeite o educando nos seus saberes, pois é a partir desses saberes que lhes será possibilitada a criação de novos conhecimentos. Sendo respeitados esses saberes, abre-se a possibilidade de usá-los na sala de aula em prol do desenvolvimento do educando como sugere o professor Paulo Freire.

\footnotetext{
"Por que não aproveitar a experiência que têm os alunos de viver em áreas da cidade descuidadas pelo poder público para discutir, por exemplo, a poluição dos riachos e dos córregos e os baixos níveis de bem-estar das populações, os lixões e os riscos que oferecem á saúde das gentes (...)” (FREIRE 2010:30)
}

Usando-se os saberes dos educandos associados à sua realidade cria-se a possibilidade de se estreitar a interação entre professor e aluno facilitando o aprendizado por meio da autonomia.

\section{Viabilizando a Autonomia do Aluno}

Essa interação baseada na troca de informações é possibilitada pelo pensamento críticoreflexivo que nos impede de crer na superioridade do educador em relação aos alunos e para que tal interação obtenha êxito é necessário também um respeito á autonomia do educando

Quando os professores se veem como superiores aos alunos eles podem compartilhar de um sentimento próximo à discriminação, e aos ideais machistas ou racistas. É necessário, portanto, que se respeite a liberdade e a autonomia do educando baseando-se na ética e na dialogicidade verdadeira em que reciprocamente se respeita a diferença com o outro. $\mathrm{O}$ respeito à autonomia e à dignidade de cada um é um imperativo ético e não um favor que podemos ou não conceder uns aos outros. (FREIRE 2010)

Um professor que respeita a autonomia do aluno provavelmente estará mais apto a assumir uma postura de inclusão quando se deparar com alunos portadores de necessidades especiais ou de uma classe oprimida. O respeito à autonomia nos aproxima da verdadeira educação para todos, sendo a autonomia do educando indispensável à dinâmica e à inclusão na sala de aula será que os professores a respeitam?

A língua é um importantíssimo traço da identidade cultural dos alunos e não há como falar em respeito aos alunos sem falar no respeito à forma com que esses alunos se expressam. Historicamente, no Brasil, a educação sempre foi voltada para as classes de elite. Portanto, 
a língua de instrução escolar é o "português-padrão", usado por essas classes. Contudo, com a democratização do ensino, alunos de língua materna sempre diferente do português idealizado, ingressaram na escola e até os dias de hoje poucas são as iniciativas para que se procure manter no discente a forma com que se expressam. O que constantemente observamos nas salas de aula é exatamente o contrário, os professores corrigem os alunos, afirmando que estes "não sabem falar". O que, segundo a sociolingüística, acarreta um preconceito lingüístico, cujas consequências são comparadas a qualquer outro preconceito.

A forma com que cada pessoa se expressa está ligada às interações com as pessoas de sua família, região e até mesmo classe social, o que faz com que tal forma de se expressar varie um pouco. Respeitar essa variação significa respeitar o aluno em si e sua identidade.

\section{Unindo C onceitos}

Um professor "não-bancário", crítico-reflexivo e que saiba conciliar seu conhecimento com a prática confere no aluno uma experiência que o estimula a aprender com entusiasmo e perseverança, possibilitando nesses alunos uma disposição para a construção de seu conhecimento.

O professor de visão autônoma, segundo Pimenta (2009), organiza e direciona, junto com os alunos, o aprendizado na sala de aula, cujos efeitos ultrapassam os muros da escola. Isso possibilita, para um futuro próximo, a criação de uma sociedade crítica, autônoma e que esteja ciente dos seus direitos e deveres como cidadãos. 


\section{Referências}

ALARCÃO, I. Formação reflexiva de professores: estratégias de supervisão. Porto: Porto Editora, 1996.

ANTUNES, C._Professores e professauros: reflexões sobre a aula e práticas pedagógicas diversas._Petrópolis: Vozes, 2007.

CONSOLO, D. A. "Formação de professores de línguas: reflexão sobre uma (re)definição de posturas pedagógicas no cenário brasileiro.” In: Freitas, A.C.; Castro, M. F. F. G. (orgs.). Língua e Literatura: ensino e pesquisa. São Paulo: Editora Contexto, 2003.

FREIRE, P. Pedagogia da autonomia: saberes necessários à prática educativa. São Paulo: Paz e Terra, 2010.

PAULINO, G. Literatura: participação e prazer. São Paulo: FTD, 1989.

PIMENTA, S.G. (org.). Saberes pedagógicos e atividade docente. São Paulo: Cortez Editora, 2009.

SANTOS, M. F. S. Identidade e Aposentadoria. São Paulo: EPU, 1990 